\title{
Cuencas de atracción y semiosis ilimitada*
}

\author{
Miguel Ángel Fuentes**
}

\begin{abstract}
Resumen
En este trabajo se argumenta en favor de la ambigüedad existente en el proceso interpretativo de textos y los mecanismos que pueden llevar a detener la denominada semiosis ilimitada. Como veremos, nuestro modo de abordar el problema puede servir en otros contextos, y las conclusiones resultantes pueden ser aplicadas a textos, obras de arte, mensajes orales, y cualquier signo en general a ser interpretado.

Palabras clave: interpretación, semiosis ilimitada, procesos estocásticos, cuentas conceptuales, atractores.
\end{abstract}

\begin{abstract}
This paper argues in favor of the ambiguity in the interpretive process and mechanisms that can lead to stop the so-called unlimited semiosis. As we shall see, our way of approaching the problem can be used in other contexts, and the resulting conclusions can be applied to text, artwork, spoken messages, and to any sign to be interpreted.
\end{abstract}

Keywords: interpretation, unlimited semiosis, stochastic processes, conceptual basin, attractors.

\section{Introducción}

Una caracterización general del giro interpretativo en la filosofía contemporánea sostendría que su aporte consiste en mostrar las condiciones de una experiencia de sentido que rechaza de plano tanto la pretensión de certeza absoluta, la presuposición de transparencia en la captación de contenidos inmediatos de conciencia, como la afirmación de una objetividad independiente a los procesos de formación histórica. Resulta claro entonces la importancia actual del problema: sobre la posibilidad de existencia de ambigüedad en la

\footnotetext{
* Recibido: mayo 2016. Aceptado: junio 2016.

** Instituto de Investigaciones Filosóficas de la Sociedad Argentina de Análisis Filosófico /

Consejo Nacional de Investigaciones Científicas y Técnicas. Buenos Aires, Argentina.

Email: fuentesm@santafe.edu
} 
interpretación y por lo tanto como salvar múltiples, tal vez infinitas, interpretaciones. Lo que nos proponemos en este texto es exponer una posible solución, basada en los procesos que llevan a una dada interpretación utilizando la experiencia y formación histórica como elementos basales.

\section{Información}

La transmisión de información y sus efectos sobre el receptor han sido abordados asumiendo que la información proviene de un emisor que codifica el mensaje y tiene la intención de comunicar. Sin embargo, es posible una noción más amplia de información, de manera que 'esta puede provenir de un emisor o de un sustrato pasible de ser tomado como fuente de información por el intérprete o receptor. De este modo la información puede provenir de un hablante, de un texto, marca o símbolo generados por un hablante o bien directamente pueden ser aspectos empíricos de un fenómeno que está siendo examinado por un intérprete, ya sea un ser vivo o un mecanismo de inteligencia artificial. Haciendo esta salvedad, lo que nos proponemos en este trabajo es concentraremos en la comunicación vía un lenguaje oral o escrito.

Es sabido que la información en la comunicación no opera de manera determinista (Dretske, 1982). La información que llega al receptor no siempre es decodificada o interpretada de la misma manera por distintos receptores y tampoco se producen los mismos resultados cuando una misma información es recibida por un mismo receptor en diferentes ocasiones. Estas características nos obligan a contemplar un aspecto indeterminista en la interacción entre información y el receptor.

Hay dos procesos en los que una comunicación entre hablantes tiene aspectos que involucran indeterminismo. Un primer aspecto tiene lugar en el proceso en el que el emisor construye el mensaje a partir de su estado conceptual. Los mensajes construidos no están en relación biyectiva con los estados conceptuales sino que podría existir un grado de indeterminación del estado conceptual a partir del mensaje. El otro proceso de indeterminación tiene lugar en el momento en que el mensaje interactúa con el estado conceptual del receptor. El modelo que presentaremos en este manuscrito aborda solamente esta última interacción.

\section{Interpretación de Textos}

La interpretación de textos o en general de signos creados por un autor para ser interpretados, puede entenderse que ocurre, de manera general, como dos formas posibles. Una primera sería estar en igual posición que la interpretación que daría el autor. La segunda sería interpretar de una forma, de las infinitas posibles según esta visión, el texto o signos en cuestión. Estas dos posiciones quedan claras en el texto de Eco (1992: 357): 
Por una parte, se admite que interpretar un texto significa esclarecer el significado intencional del autor o, en todo caso, su naturaleza objetiva, su esencia, un esencia que, como tal, es independiente de nuestra interpretación. Por la otra se admite, en cambio, que los textos pueden interpretarse indefinidamente.

Como observa Eco, ambas opciones son ejemplos de un fanatismo epistemológico, difíciles de sostener empíricamente. La primera opción contiene un alto nivel de determinismo, el cual actúa en, al menos, dos etapas. Una primera sería superar la etapa creativa del autor, como elector de múltiples opciones, y dar a luz una obra que presente una única interpretación. La segunda etapa recae totalmente en la interpretación que un tercero da respecto del texto. Nótese como en esta simplificación del proceso creativo/interpretativo tenemos al menos tres actores: autor, obra y observador (a este último lo llamamos así para evitar posibles confusiones con otros conceptos).

Tenemos entonces al menos algo parecido a lo ilustrado en la Fig. 1. Allí mostramos como de todas las posibilidades con las que cuenta el autor, el resultado final es solo un texto (esquematizado por una sola flecha desde el autor hasta el texto final). Cabría preguntarse entonces si el texto corresponde exactamente a la intención del autor. Obviamente aquí tenemos un primer problema a la hora de decidir por una relación uno a uno entre el estado mental del autor, al crear el texto, y el texto en cuestión. Creo que no caben dudas de esta imposibilidad, o al menos bajas probabilidades de que esta relación exista dada la alta cantidad de posibilidades, del orden $N^{20}$ (con $N$ el número de palabras utilizadas en un texto). En definitiva tendremos a lo más una buena aproximación de lo que el autor quiso expresar en el momento de su creación.

La segunda flecha va desde el texto en cuestión al observador ¿Qué interpreta el observador? Podemos decir sin mucho error que su interpretación depender de su estado mental. Si es posible dejar fuera todo contexto histórico, podremos decir entonces que quizás exista una aproximación cercana del texto con su interpretación. Pero finalmente, en esta interpretación, se recurrir al uso de conceptos que no dejan de tener cargas culturales, sociales, etc., que no permitirán lo unívoco en la relación texto-interpretación al considerar diferentes observadores.

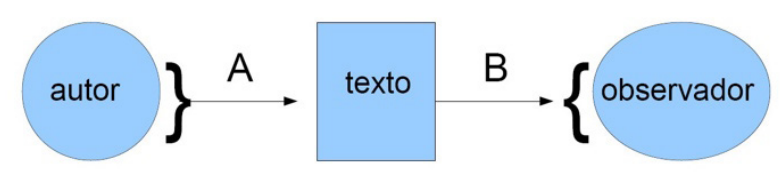

Figura 1: Esquema mínimo del proceso creativo/interpretativo. Las llaves indican la variedad de posibilidades, tanto del autor como del observador, a la hora de dejar plasmadas las ideas de su obra o interpretarla. 


\section{Interpretación infinita}

Como se muestra en el en la Fig. 1, los elementos básicos que llevan finalmente a una interpretación de un dado texto son al menos tres. Cabe preguntarnos entonces, como ya habíamos anticipado en más arriba, si el esquema mostrado en la Fig.1 se aplica a la situación de producción e interpretación unívoca. Creemos que no es así. Lo que creeremos sucede nos llevará luego a conectar estos procesos con situaciones parecidas, aunque para nada equivalentes, a lo que sucede en la deriva hermética o en la semántica de Pierce. La idea básica es volver a estudiar de manera critica el proceso que va del texto al observador. Algo similar ocurrirá en el proceso desde el autor al texto definitivo. Esta similitud puede pensarse como una simetría inversa.

En el caso de deriva hermética la connotación, e interpretación, da una idea de crecimiento ad infinitum, como el ejemplificado en la Fig. 2. Según Eco $(1992,360)$, este diagrama "quisiera dar una idea del crecimiento connotativo de tipo canceroso".
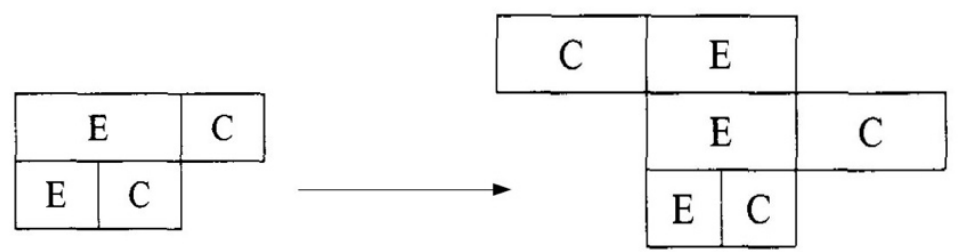

Figura 2: Diagrama que da una idea del crecimiento connotativo de tipo canceroso (ibid,1982).

Este caso presenta similares características que el fenómeno de deriva en cadenas de semejanzas, donde una serie de cosas: A, B, C, D, E, es analizada en términos de propiedades a, b, c, d, e, f, g, h. Si estas cosas comparten algunas de las propiedades, como el caso ejemplificado en la Fig. 3, puede verse como dos cosas sin propiedades en común (como A y E) están vinculadas mediante esta cadenas de semejanzas.
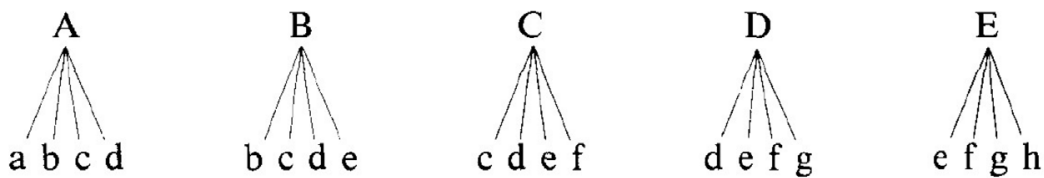

Figura 3: Deriva en cadena de semejanzas de familia. Las cosas A y E no comparten ninguna propiedad salvo mediante la cadena de propiedades desde A hasta E. 
En cambio, en el proceso de semiosis ilimitada "cada objeto inmediato de un representamen es interpretado por otro signo, y así sucesivamente, potencialmente hasta infinito" (Eco, 1982: 361), Fig. 4.

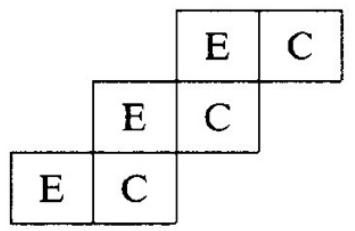

Figura 4: Semiosis ilimitada. Cada objeto inmediato es interpretado por otro signo, pudiendo repetirse este proceso hasta el infinito.

Notar que todas estas tradiciones llevan a un problema insalvable, el cual podría definirse como la divergencia de la interpretación. Aunque estrictamente no son equivalentes, estas posturas tienen una dinámica similar. Si estudiamos detenidamente estos procesos podemos observar que parten de un concepto inicial el cual se supone unívoco, aquí ya comienza a aparecer el primer problema poco advertido por estas teorías, el cual se refiere a la relación unívoca entre la intención del autor y el texto que lo representa. Como mencionamos, esto puede entenderse como el proceso anti-simétrico al que ocurre con el observador. Definido entonces el concepto inicial, la interpretación ir navegando en diferentes paisajes conceptuales que son asociaciones con el concepto original. El punto clave es que ésta evolución no encuentra ningún tipo de barrera, y solo está sujeta de manera determinista a conceptos anteriormente utilizados.

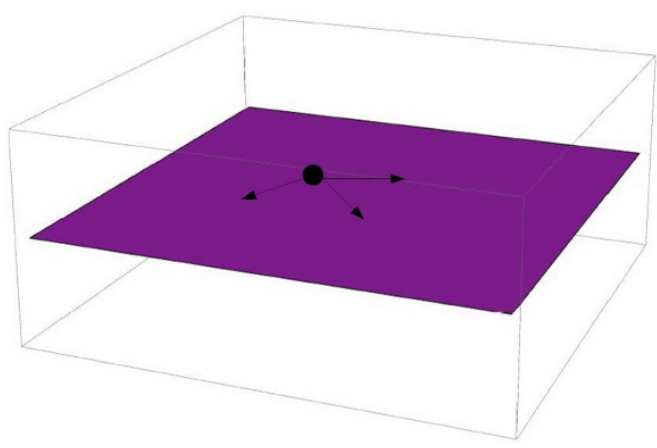

Figura 5: Divergencia conceptual clásica. Un dado concepto inicial puede evolucionar hacia otros inmediatos sin ninguna obstrucción, esta divergencia dependerá solo de la dinámica propuesta. 
A continuación, escribiremos esto último de una manera abstracta, que nos servirá luego para entender las diferencia profundas entre estas teorías y la presentada en este trabajo. Diremos entonces que la evolución de los conceptos que están siendo interpretados obedece a una dinámica del tipo

$$
\frac{d x}{d t}=F[x, t]
$$

donde $d x / d t$ indica la evolución temporal de conceptos $x$ a un tiempo $t$. Mientras que $F[$.$] es una función determinista que no presenta puntos de equi-$ librio, es decir no tiene puntos donde la evolución se anula, lo cual habría permitido que el proceso interpretativo finalizara (ver Fig. 5).

\section{Cuencas conceptuales}

Consideremos que el observador posee una red de conceptos estructurada, de manera que una porción de esa red es relevante para la interacción con cierta información (Perlovsky, 2001). En tal red cada nodo está representado por una cuenca con un punto central o atractor que constituye el concepto paradigmático o prototípico. La cuenca conceptual representa el alcance del concepto en sus diferentes aspectos. Esta red de cuencas conceptuales puede tener una estructura de diferentes niveles, cuestión que no abordaremos en la presente comunicación, aunque tales niveles podrán ser relevantes para la modelización de las relaciones entre conceptos o clases conceptuales (Gärdenfors, 2000). En particular es de esperar que la integración de varios aspectos conceptuales para producir un concepto más complejo pueda involucrar un cambio de nivel y procesos emergentes. Del mismo modo, los conceptos relacionales parecerían corresponder a cuencas que son el resultado de conexiones entre conceptos de niveles inferiores.

El modelo presentado a continuación, el cual puede verse en extenso en (Fuentes y Miguel, 2013; y Fuentes et al., 2014), toma el estado del receptor como perteneciente a una dimensión conceptual x. Esta dimensión conceptual estará inmersa en un paisaje, o potencial conceptual $\mathrm{V}[\mathrm{x}]$, el cual dar cuenta de cuan probable es un dado concepto en esa cuenca.

La dinámica propuesta en este paisaje conceptual, es de la forma:

$$
\frac{d x}{d t}=\gamma V[x]+\varepsilon \xi(t),
$$

El parámetro $\gamma$ indica la velocidad de relajación de un dado concepto inicial activado por un estímulo entrante, al cual podríamos indicarlo como la condición inicial. La dinámica estocástica está dada por el término $\xi(t)$, el cual 
formalmente es un término de ruido blanco con una amplitud caracterizada por $\varepsilon$. Este término da cuenta de la capacidad de explorar conceptos cercanos y permitir asociaciones con cierta probabilidad pesadas por el potencial.

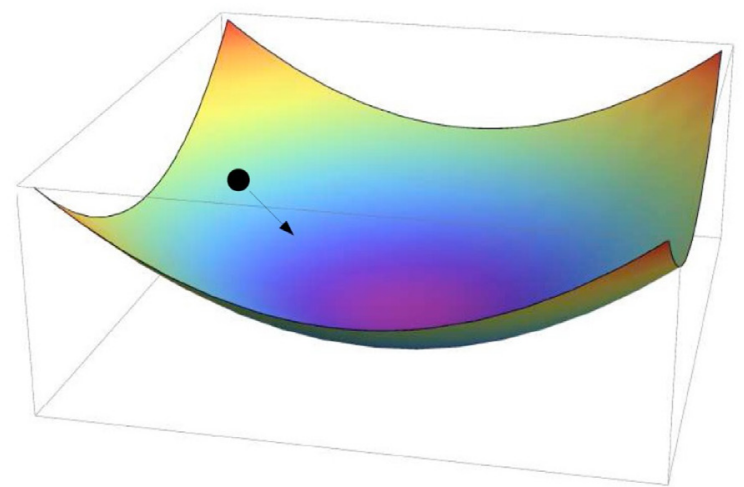

Figura 6: Cuencas conceptuales. Se esquematiza la diferencia cualitativa importante de la dinámica interpretativa propuesta en este trabajo. La interpretación converge hacia el mínimo de la cuenca conceptual.

De esta manera, si consideramos estático al potencial $V[x]$, el receptor interpretar la información o estímulo recibido en términos de conceptos relacionados con el potencial conceptual y el camino estocástico realizado, el cual finalmente relajar a alguno de los mínimos relativos del potencial (concepto de mayor probabilidad asociada con una cuenca).

Dicho en otros términos, el proceso de interpretación tiene, por parte del receptor, un aporte activo en dos aspectos. Por un lado el estímulo entrante activa una cierta zona de la topografía conceptual y esa zona tiene un proceso de relajación hacia alguna de las cuencas que actúan como atractores propios del receptor. Por otra parte el proceso de relajación no sigue siempre el mismo derrotero en ese paisaje dejando en cada ocasión una huella en particular, modificando el propio paisaje, como veremos más abajo. Este derrotero no determinado a priori pero determinado post factum est modelizado por el término estocástico analizado anteriormente. En resumen, el receptor es doblemente activo respecto de la información entrante dando al modelo la capacidad de otorgar al intérprete o receptor un papel importante en la comunicación.

Hasta aquí la evolución dentro de la cuenca conceptual, la cual fue tomada de manera estática. Lo que haremos a continuación es proponer una posible dinámica para ella con la finalidad de permitir cambios permanentes en el potencial, tal como anticipamos al mencionar que cada derrotero en el proceso de relajación puede dejar una huella en la topografía misma. Propondremos entonces que el potencial cambiar la siguiente manera su forma durante la dinámica de la siguiente manera: 


$$
\frac{d x}{d t}=\gamma P(x, t-\tau)+\xi(\mathrm{t}) .
$$

El primer término de esta ecuación muestra como el proceso de relajación hacia un concepto depende de la probabilidad $\mathrm{P}(x, t-\tau)$ anterior que existe en la cuenca conceptual. Notar el tiempo $\tau$ que representa el retardo en el proceso y es un parámetro propio de la constitución de la entidad tomada como intérprete.

Esta forma de pensar la dinámica resulta muy novedosa y fructífera. Puede verse cómo el proceso se autogenera, es decir: cuántas más visitas ocurran en un concepto dado, más aumentar la probabilidad asignada para ese concepto. Así también la búsqueda en el espacio de conceptos en un dado nivel es determinada por la derivada de la probabilidad, lo cual es plausible ya que el proceso de búsqueda sería como ir navegando hacia conceptos de probabilidad más alta.

Esta característica del modelo permite dar cuenta de la modificación conceptual que se produce cuando el concepto activado por el estímulo no coincide con el concepto prototípico que opera como mínimo en la cuenca conceptual correspondiente. Este aspecto tiene la virtud de dar cuenta de un tipo de aprendizaje en el que la cuenca inicial se ve modificada en correspondencia con un nuevo alcance del concepto por el uso, una y otra vez, de zonas de la cuenca no coincidentes con el mínimo.

\section{Comentarios finales}

Con unos pocos parámetros el modelo parece adecuado en representar los procesos básicos de surgimiento de cuencas conceptuales, cambio del alcance de una cuenca conceptual y de la modificación de su mínimo asociado al concepto prototípico de la cuenca, desaparición de la cuenca y facilitación o dificultad en la modificabilidad del espacio conceptual en diferentes etapas de procesamiento de estímulos. Además permite de una manera natural la convergencia y detención de la semiosis ilimitada.

Rescata desde el comienzo la característica de que la comunicación no es un proceso determinista. Esto permite mostrar la posibilidad de equívoco y ambigüedad en la interpretación.

Por otra parte, al proponer que en el receptor existe una topografía previa que oficia como potencial en el que tiene lugar un proceso de relajación de un concepto activado por el estímulo entrante, permite comprender por qué la comunicación en términos generales, es efectiva. Si el proceso fuera tan indeterminista que no existiera siquiera una tendencia del receptor a organizar los estímulos sobre la base de cierta red conceptual, el lenguaje mismo sería incomprensible, el éxito en la comunicación quedaría sin explicación o bien sería milagroso y la entidad receptora no merecería el apelativo de intérprete. 
Es decir, por un lado modelo explica por qué un receptor puede comprender o decodificar de modo diferente un mismo mensaje en ocasiones diferentes y por otra parte permite comprender el éxito en el uso del lenguaje ya que tanto emisor como receptor logran comunicarse en virtud de que el receptor va recibiendo información que interactúa con su configuración conceptual, incluso de manera de modificarla de modo permanente.

En este sentido permite dar cuenta del aprendizaje mediante adquisición de información que es capaz de generar nuevos conceptos o desactivar el uso de conceptos anteriores, modificar las relaciones entre conceptos, el alcance de los conceptos, el concepto prototípico asociado a cada cuenca e incluso la composición o integración de los conceptos cuando se los concibe como el resultado de alguna operación entre conceptos de niveles inferiores. Esto da por resultado una dinámica en la estructura categorial.

El modelo también contempla que la asociación de conceptos pueda dar lugar a conceptos de otro orden y mantener una interacción entre conceptos de diferentes niveles. Un fenómeno que será de mucho interés para esta investigación es la posibilidad que brinda este modelo para dar cuenta de cambios de fase, o sea, reordenamientos de la red por efectos colectivos.

En particular habrá estímulos que, o bien por su largo tiempo de relajación (configuraciones con un valor muy bajo del coeficiente de determinación) o bien por el excesivo apartamiento del concepto activado respecto de los conceptos prototípicos, serán candidatos más probablemente al rechazo que a la modificación de las cuencas. Sin embargo, si se continúa con el proceso de estímulos hipotéticos en los que el receptor se ve obligado una y otra vez a procesar conceptos todos alejados suficientemente de sus conceptos prototípicos, puede ocurrir que se llegue a una situación en la que un conjunto amplio de conceptos puedan reacomodarse de manera drástica y conjuntamente dando como resultado un cambio de fase, una configuración totalmente nueva de la topografía de cuencas asociada a lo que en otros contextos cuenta como cambio de clasificación.

Creemos que esta situación sería una buena representación del cambio de cosmovisión que puede tener lugar cuando varios conceptos cambian de manera conjunta y adquieren una nueva red de conexiones entre cuencas conceptuales.

De este modo el modelo sería también fructífero en dar cuenta de por qué el cambio de teorías o el cambio de cosmovisión tiene el aspecto de un cambio rupturista ya que queda representado por un cambio de fase en el paisaje conceptual. 


\section{Referencias bibliográficas}

Eco, U. (1992): Los límites de la interpretación. Barcelona: Editorial Lumen.

Dretske, F. (1982): Knowledge and the Flow of Information. Cambridge, Massachusetts: The MIT Press.

Gardenfors, P. (2000): Conceptual Spaces. The Geometry of Thought. Cambridge, Massachusetts: The MIT Press.

Gende, C.E. (2010): Problemas filosóficos de la interpretación: del lenguaje de los interpretantes al lenguaje del intérprete. Seminario de Posgrado. Neuquén: Universidad Nacional del Comahue.

Perlovsky, L. (2001): Neural Networks and Intellect: Using Model-Based Concepts. Oxford: Oxford University Press.

Fuentes, M.A., Miguel, H. (2013): "Self Generated Dynamic Landscape", en Physica A 392: 2492-2497.

Fuentes et al. (2014): "Frontier in Computational Neuroscience. Stochastic model predicts evolving preferences in the Iowa gambling task", en Frontiers in Computational Neuroscience 5: 167. 